\title{
Pharmacological prevention of serious anaphylactic reactions due to iodinated contrast media: systematic review
}

\author{
Martin R Tramèr, Erik von Elm, Pierre Loubeyre, Conrad Hauser
}

\begin{abstract}
Objective To review the efficacy of pharmacological prevention of serious reactions to iodinated contrast media.

Design Systematic review.

Data sources Systematic search (multiple databases, bibliographies, all languages, to October 2005) for randomised comparisons of pretreatment with placebo or no treatment (control) in patients receiving iodinated contrast media.

Review methods Trial quality was assessed by all investigators. Information on trial design, population, interventions, and outcomes was abstracted by one investigator and cross checked by the others. Data were combined by using Peto odds ratios with $95 \%$ confidence intervals.

Results Nine trials (1975-96, 10011 adults) tested $\mathrm{H}_{1}$ antihistamines, corticosteroids, and an $\mathrm{H}_{1}-\mathrm{H}_{2}$ combination. No trial included exclusively patients with a history of allergic reactions. Many outcomes were not allergy related, and only a few were potentially life threatening. No reports on death, cardiopulmonary resuscitation, irreversible neurological deficit, or prolonged hospital stays were found. In two trials, $3 / 778$ $(0.4 \%)$ patients who received oral methylprednisolone $2 \times 32 \mathrm{mg}$ or intravenous prednisolone $250 \mathrm{mg}$ had laryngeal oedema compared with 11/769 (1.4\%) controls (odds ratio $0.31,95 \%$ confidence interval 0.11 to 0.88 ). In two trials, $7 / 3093(0.2 \%)$ patients who received oral methylprednisolone $2 \times 32 \mathrm{mg}$ had a composite outcome (including shock, bronchospasm, and laryngospasm) compared with 20/2178 (0.9\%) controls (odds ratio $0.28,0.13$ to 0.60$)$. In one trial, $1 / 196(0.5 \%)$ patients who received intravenous clemastine $0.03 \mathrm{mg} / \mathrm{kg}$ and cimetidine 2-5 $\mathrm{mg} / \mathrm{kg}$ had angio-oedema compared with 8/194 (4.1\%) controls (odds ratio $0.20,0.05$ to 0.76 ).

Conclusions Life threatening anaphylactic reactions due to iodinated contrast media are rare. In unselected patients, the usefulness of premedication is doubtful, as a large number of patients need to receive premedication to prevent one potentially serious reaction. Data supporting the use of premedication in patients with a history of allergic reactions are lacking. Physicians who are dealing with these patients should not rely on the efficacy of premedication.
\end{abstract}

\section{Introduction}

Each year, about 60 million doses of iodinated contrast media are used worldwide. ${ }^{1}$ Iodinated contrast media can cause anaphylaxis (itching, urticaria, angio-oedema, and bronchospasm or arterial hypotension and shock) within minutes after administration. The precise mechanism of anaphylaxis to iodinated contrast media is unknown, although release of hista- mine and triggering of mast cells are related to severe reactions and an IgE related mechanism is suspected in some cases. ${ }^{2}$

Despite the fact that the increased use of non-ionic iodinated contrast media has been associated with a decrease in the incidence of mild to moderate, and possibly severe, reactions, prophylactic drug regimens that aim to decrease the incidence of reactions (premedication) are still widely used in clinical practice. On the basis of observational data, Greenberger and Patterson concluded in 1991 that patients with a previous reaction to high osmolality iodinated contrast media should receive oral prednisone and diphenhydramine with or without ephedrine. ${ }^{3}$ Since then, professional organisations have recommended a variety of regimens and combinations of methylprednisolone with or without an antihistamine, ${ }^{4}$ oral prednisolone or methylprednisolone, ${ }^{5}$ or intravenous hydrocortisone and intramuscular diphenhydramine. ${ }^{6}$

Undoubtedly, considerable variation exists in recommended pretreatment regimens. Published guidelines are based on observational data, and to what extent physicians who are dealing with patients with or without a history of allergic reactions who are receiving iodinated contrast media can rely on the efficacy of pretreatment remains unclear. We set out to review the efficacy of pharmacological prevention of serious, potentially life threatening reactions to iodinated contrast media.

\section{Material and methods}

\section{Search strategy}

We searched for reports of trials (without language restrictions) that tested premedication in patients who received iodinated contrast media. We searched in Medline, Oldmedline, Embase, HealthSTAR, and CINAHL by using a comprehensive list of generic names and brand names of contrast media, steroids, antihistamines, and ephedrine and key words for adverse drug reactions (for instance, allerg\$ or hypersensitiv\$) and for prevention and prophylaxis (for instance, prevent\$ or protect\$). The search period was 1950 to October 2005. We searched the Cochrane controlled trials register and reviewed bibliographies of relevant reviews $s^{357}$ and included articles. Our prespecified inclusion criteria were random allocation of patients, use of premedication alone or in combination, presence of a placebo or a no treatment control group, and reporting of presence or absence of allergic reactions.

\section{Outcomes}

These trials reported on a large variety of outcomes and combinations of outcomes. We classified them as "distinct allergy 
related symptoms," "symptom categories" (grades), "non-specific symptoms," and "adverse drug reactions." Two large trials reported exclusively on arbitrary categories of symptom combinations (grades) according to the presumed degree of severity of the symptoms. ${ }^{\mathrm{w} 1 \mathrm{w} 2}$ Grade 1 included a single episode of emesis, nausea, sneezing, and vertigo. Grade 2 consisted of hives, erythema, emesis more than once, and fever or chills (or both). Grade 3 comprised clinical shock, bronchospasm, laryngospasm, laryngeal oedema, loss of consciousness, convulsions, decrease or increase in blood pressure, cardiac arrhythmia, angina, angiooedema, or pulmonary oedema.

\section{Data extraction}

One investigator (EvE) abstracted the articles; the others independently validated the extracted data. Two investigators, an allergologist $(\mathrm{CH})$ and an anaesthetist (MRT), decided together for each symptom whether it was most likely allergy related, on the basis of the description of typical features reported in the original trials. They also decided for each symptom whether it was serious (that is, potentially life threatening). We regarded symptoms as potentially life threatening when they had the potential to deteriorate towards a status in which ventilatory or haemodynamic support would become necessary (for instance, laryngeal oedema needing tracheal intubation or arterial hypotension needing catecholamines). When symptom localisation was unclear (angio-oedema may be cutaneous or respiratory), we assumed that the more serious (in this case, laryngeal oedema) had occurred. All investigators read all included reports independently to assess the quality of randomisation, concealment of treatment allocation, blinding (patient, caregiver, observer), and patient follow-up. We compared extracted data and resolved disagreements by discussion.

\section{Data synthesis}

We calculated dichotomous data as Peto odds ratios (as many zero cells existed) with $95 \%$ confidence intervals; an odds ratio $<1$ suggested efficacy with premedication. When we combined data from more than two trials, we did formal heterogeneity testing (we considered $\mathrm{P}>0.1$ to be homogeneous) and calculated the $I^{2}$ value as a measure of the degree of inconsistency between the trial results. ${ }^{8}$

Some trials reported on several similar outcomes. As more than one symptom could have occurred in the same patient, we had to select one for analysis. We knowingly selected the outcome with the most pronounced treatment effect (that is, with the lowest odds ratio). We assumed that this would create a bias towards an overestimation of the efficacy of premedication; this overestimation would have to be taken into account when interpreting the results of the analyses. We used Stata version 7 for meta-analyses.

\section{Results}

\section{Search results}

Of 64 potentially relevant reports, we excluded 55; most compared different contrast media (fig 1). We identified one cluster of two reports that originated from a single trial; we regarded the older report as the main article,$^{\mathrm{w} 1}$ and excluded the copy. ${ }^{9}$ Nine trials, published between 1975 and 1996, met our inclusion criteria (table 1). ${ }^{\text {wl-w9 } 9}$ The total number of participants was $10011 ; 6108$ received premedication. All but two reports were in English. ${ }^{\mathrm{w} 4}$ w9 The median trial size was 299 patients (range 66-6763). In no report was an adequate randomisation method described, and only in one was treatment allocation concealed. ${ }^{\mathrm{w} 1}$ In four reports, evidence existed of adequate blinding of patients,

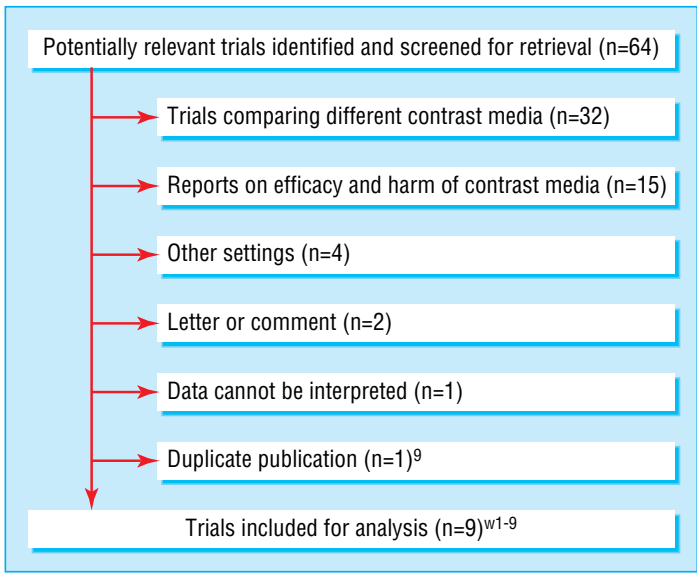

Fig 1 Flowchart of retrieved, excluded, and analysed reports

caregivers, and observers. ${ }^{\mathrm{w1}-\mathrm{w} 3 \mathrm{w} 8}$ No report described a complete patient follow-up that enabled an intention to treat analysis.

\section{Patients}

All trials included adults. In three, patients with a history of reaction to iodinated contrast media were excluded. ${ }^{\mathrm{w} 1 \mathrm{w} 3 \mathrm{w} 6}$ Bertrand et al also excluded patients with a history of allergy, atopy, or drug hypersensitivity. ${ }^{\text {w3 }}$ The other six did not specify exclusion criteria and only inconsistently specified the percentage of patients who had a history of at least one previous serious reaction or of those who had never had iodinated contrast media.

\section{Premedications}

Five trials tested $\mathrm{H}_{1}$ antihistamines (hydroxyzine, ${ }^{\mathrm{w} 3}$ clemastine, ${ }^{\mathrm{w} 6 \mathrm{w} 9}$ chlorpheniramine, ${ }^{\mathrm{w} / 7}$ dimenhydrinate $\left.{ }^{\mathrm{w} 8}\right)$, five tested corticosteroids (betamethasone, ${ }^{\mathrm{w} 4}$ dexamethasone, ${ }^{\mathrm{w} 5}$ methylprednisolone, ${ }^{\mathrm{w1}}$ w2 prednisolone $\left.{ }^{w 6}\right)$, and one tested an $\mathrm{H}_{1}-\mathrm{H}_{2}$ combination (clemastine-cimetidine) $^{\mathrm{w} 6}$ (table 1). None tested a steroidantihistamine combination, and we found no reports on ephedrine.

\section{Contrast media}

In eight trials, iodinated contrast media were given intravenously, and in one it was given intrathecally (table 1). Three trials used a non-ionic low osmolar medium (ioxaglate, ${ }^{\mathrm{w} 8}$ iohexol or ioversol ${ }^{\mathrm{w} 2}$ w5). Two trials used an ionic high osmolar medium (amidotrizoat sodium or meglumine $\left.{ }^{w 6}{ }^{w 9}\right)$. Chevrot et al used four different ionic media, ${ }^{\mathrm{w} 4}$ but $92 \%$ of the patients received ioxithalamate, an ionic high osmolar medium. In one trial, both an ionic high osmolar medium (meglumine) and a non-ionic low osmolar medium (ioxaglate) were injected. ${ }^{\text {w3 }}$ In one trial, media were specified as ionic only. ${ }^{\mathrm{w} 1}$ Finally, one trial did not specify the type of medium. ${ }^{\mathrm{7}}$

\section{Radiological interventions}

Radiological interventions were urography in five trials, ${ }^{\mathrm{w} 2-\mathrm{w} 4} \mathrm{w} 6 \mathrm{w} 9$ computed tomography scan in three trials, ${ }^{\text {w2-w4 }}$ venography or arteriography in three trials, ${ }^{\mathrm{w} 3 \mathrm{w} 4 \mathrm{w8}}$ and myelography, ${ }^{\mathrm{w5}}$ pyelography, ${ }^{\mathrm{w} 7}$ or cholangiography ${ }^{\mathrm{w} 9}$ in one trial each (table 1). In one trial, the type of imaging procedure was not specified. ${ }^{\mathrm{w} 1}$

\section{Outcomes}

Table 2 presents the large variety of outcomes that were reported in these trials.

\section{Distinct allergy related symptoms}

Three trials reported on arterial hypotension. We regarded hypotension as potentially life threatening, although none of the 
Research

\begin{tabular}{|c|c|c|c|c|c|}
\hline References & $\begin{array}{l}\text { Quality of data } \\
\text { reporting }(\mathrm{R}-\mathrm{C}-\mathrm{B}-\mathrm{F})^{*}\end{array}$ & Premedication and control (No analysed) & $\begin{array}{l}\text { Radiological intervention } \\
\text { (No analysed) }\end{array}$ & Excluded patients & Contrast medium \\
\hline $\begin{array}{l}\text { Bertrand et al, } \\
1992^{\mathrm{w3}}\end{array}$ & $1-0-2-0$ & Hydroxyzine 100 mg P0 12 h before (200); placebo PO (200) & $\begin{array}{l}\text { IV urography (297); CT } \\
\text { scan (93); venography (10) }\end{array}$ & $\begin{array}{l}\text { Allergy, atopy, previous } \\
\text { reaction to CM, drug } \\
\text { hypersensitivity }\end{array}$ & Meglumine; ioxaglate \\
\hline $\begin{array}{l}\text { Chevrot et al, } \\
1988^{\mathrm{w} 4}\end{array}$ & $1-0-0-0$ & Betamethasone 8 mg IV with CM (109); no treatment (112) & $\begin{array}{l}\text { IV urography; CT scan; } \\
\text { venography }\end{array}$ & None & $\begin{array}{l}4 \text { ionic IV CM (92\%: } \\
\text { ionic high osmolar) }\end{array}$ \\
\hline $\begin{array}{l}\text { Ginsberg et al, } \\
1996^{\mathrm{w}} \mathrm{s}\end{array}$ & $1-0-1-0$ & $\begin{array}{l}\text { Dexamethasone } 4 \mathrm{mg} \mathrm{PO} \text { 4×/d for } 24 \mathrm{~h} \text { (42); placebo PO } \\
\text { (44) }\end{array}$ & Myelography & None & lohexol (intrathecal) \\
\hline $\begin{array}{l}\text { Lasser et al, } \\
1987^{\mathrm{w1}}\end{array}$ & $1-1-2-0$ & $\begin{array}{l}\text { Methylprednisolone } 2 \times 32 \mathrm{mg} \text { PO evening and } 2 \mathrm{~h} \text { before } \\
\text { (2513, group 1); methylprednisolone } 32 \mathrm{mg} \text { PO } 2 \mathrm{~h} \text { before } \\
\text { (1759, group 2); placebo PO as for group } 1 \text { (1603); placebo } \\
\text { PO as for group } 2 \text { (888) }\end{array}$ & IV injection & $\begin{array}{l}\text { Previous reaction } \\
\text { to } \mathrm{CM}\end{array}$ & Any ionic \\
\hline $\begin{array}{l}\text { Lasser et al, } \\
1994^{\mathrm{w} 2} \\
\end{array}$ & $1-0-2-1$ & $\begin{array}{l}\text { Methylprednisolone } 2 \times 32 \mathrm{mg} \text { PO 6-24 h and } 2 \mathrm{~h} \text { before } \\
\text { (580); placebo PO (575) }\end{array}$ & Urography; CT scan & None & lohexol; ioversol \\
\hline Ring et al, $1985^{\mathrm{w}}$ & $1-0-0-1$ & $\begin{array}{l}\text { Prednisolone } 250 \mathrm{mg} \mathrm{IV} \mathrm{(198);} \mathrm{clemastine} 0.03 \mathrm{mg} / \mathrm{kg} \text { IV } \\
\text { (191); clemastine } 0.03 \mathrm{mg} / \mathrm{kg} \text { + cimetidine } 2-5 \mathrm{mg} / \mathrm{kg} \\
\text { (according to renal function) IV (196); placebo (saline) IV } \\
\text { (194); timing not specified }\end{array}$ & IV urography & $\begin{array}{l}\text { Previous reaction } \\
\text { to } \mathrm{CM}\end{array}$ & $\begin{array}{l}\text { Meglumine; } \\
\text { amidotrizoate }\end{array}$ \\
\hline Small et al, $1982^{w 7}$ & $1-0-0-0$ & $\begin{array}{l}\text { Chlorpheniramine } 10 \mathrm{mg} \text { SC } 15 \text { min before (78); placebo } \\
\text { (saline) SC (71); no treatment (71) }\end{array}$ & IV pyelography & None & Not specified \\
\hline Smith et al, $1995^{\text {w8 }}$ & $1-0-2-1$ & $\begin{array}{l}\text { Dimenhydrinate } 25 \mathrm{mg} \text { IV } 15 \text { to } 45 \mathrm{~min} \text { before (150); placebo } \\
\text { (saline) IV (149) }\end{array}$ & Arteriography & None & loxaglate \\
\hline Wicke et al, $1975^{\mathrm{wa}}$ & $1-0-1-0$ & Clemastine 2 mg IV with CM (92); placebo (saline) IV (116) & $\begin{array}{l}\text { Urography (148); } \\
\text { cholangiography (60) }\end{array}$ & None & $\begin{array}{l}\text { Amidotrizoate; } \\
\text { meglumine }\end{array}$ \\
\hline
\end{tabular}

$\mathrm{CM}=$ contrast medium; $\mathrm{CT}=$ computed tomography; IV=intravenously; $\mathrm{PO}=$ orally; $\mathrm{SC}=$ subcutaneously.

${ }^{*}$ Randomisation (R): $0=$ none, $1=$ mentioned but not specified, $2=$ =mentioned and adequate. Concealment of treatment allocation (C): $0=$ none; $1=y e s$. Blinding (B): $0=$ none, $1=$ incomplete, $2=$ patient and caregiver and observer blinded. Follow-up (F): 0=none reported, 1=incomplete, 2=complete (intention to treat analysis possible).

reports provided a definition of hypotension. Intravenous dimenhydrinate $25 \mathrm{mg},{ }^{\text {w8 }}$ intravenous betamethasone $8 \mathrm{mg},{ }^{\text {w4 }}$ and oral methylprednisolone $2 \times 32 \mathrm{mg}$ were tested. ${ }^{\mathrm{w} 2}$ None of the 689 patients who received steroids had hypotension compared with $3 / 687(0.4 \%)$ controls (odds ratio $0.14,95 \%$ confidence interval 0.01 to 1.30 ) (fig 2).

Three trials reported on respiratory symptoms. Oral hydroxyzine $100 \mathrm{mg},{ }^{\text {w3 }}$ intravenous clemastine $0.03 \mathrm{mg} / \mathrm{kg}$ and

\begin{tabular}{|c|c|}
\hline Outcome & Reporting \\
\hline \multicolumn{2}{|c|}{ Distinct allergy related symptoms or combinations of symptoms } \\
\hline Haemodynamic & Hypotensionw2 w4 w8 \\
\hline Respiratory & $\begin{array}{l}\text { Bronchospasm, }{ }^{\text {w2 }} \text { w3 laryngeal oedema, }{ }^{\text {w2 }} \text { urticaria or angio-oedema } \\
\text { (combined) }{ }^{66}\end{array}$ \\
\hline Cutaneous & $\begin{array}{l}\text { Erythema, }{ }^{\text {w8 }} \text { facial or eyelid oedema, }{ }^{\text {w8 }} \text { periorbital oedema, }{ }^{\text {w2 }} \text { flush,w6 } \\
\text { flush or erythema, }{ }^{\text {w2 }} \text { hives, }{ }^{\text {w2 }} \text { w8 w9 } \text { pruritus, }{ }^{\text {w2 w8 }} \text { hives or pruritus, } \\
\text { urticaria" }{ }^{\text {w3 w9 }}\end{array}$ \\
\hline \multicolumn{2}{|c|}{ Arbitrary symptom combinations (grades) } \\
\hline Grade 1 & Single episode of emesis, nausea, sneezing, or vertigo ${ }^{\mathrm{w} 1 \mathrm{w} / 2}$ \\
\hline Grade 2 & $\begin{array}{l}\text { Hives, erythema, emesis more than once, and fever or chills (or } \\
\text { both) }\end{array}$ \\
\hline Grade 3 & $\begin{array}{l}\text { Clinical "shock," bronchospasm, laryngospasm or oedema, loss of } \\
\text { consciousness, convulsions, fall in blood pressure, increase in } \\
\text { blood pressure, cardiac arrhythmia, angina, angio-oedema, or } \\
\text { pulmonary oedema w1 w2 }\end{array}$ \\
\hline \multicolumn{2}{|c|}{ Non-specific symptoms or symptom combinations } \\
\hline $\begin{array}{l}\text { Any non-specific } \\
\text { symptoms }\end{array}$ & $\begin{array}{l}\text { Any reaction, w1-w5 w7-w9 } \text { other objective or subjective symptoms, }{ }^{\text {w6 }} \\
\text { treatment needed }{ }^{w 1}\end{array}$ \\
\hline $\begin{array}{l}\text { Non-specific respiratory } \\
\text { symptoms }\end{array}$ & Dyspnoea, ${ }^{\text {w2 }}$ respiratory symptoms, ${ }^{\text {w6 }}$ cough, ${ }^{w 9}$ tachypnoeaw9 \\
\hline $\begin{array}{l}\text { Non-specific } \\
\text { cardiovascular } \\
\text { symptoms }\end{array}$ & $\begin{array}{l}\text { Hypertension, }{ }^{\text {w2 }} \text { change in blood pressure, }{ }^{\text {w9 }} \text { palpitations, }{ }^{\text {w2 }} \\
\text { tachycardia, }{ }^{\text {w9 }} \text { heat sensation }{ }^{w 6} \text { w9 }\end{array}$ \\
\hline Emetic symptoms & 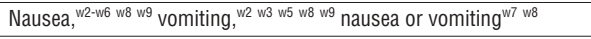 \\
\hline Other symptoms & 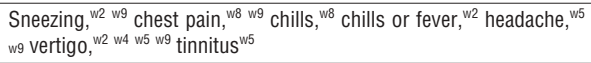 \\
\hline \multicolumn{2}{|l|}{ Adverse drug reactions } \\
\hline $\begin{array}{l}\text { Dexamethasone, } \\
\text { methylprednisolone }\end{array}$ & $\begin{array}{l}\text { Reaction to premedication (bitter taste, nausea, headache), }{ }^{\text {,2 }} \\
\text { insomnia, }{ }^{\text {w5 }} \text { dyspepsia, }{ }^{\text {w5 }} \text { spinal pain"w5 }\end{array}$ \\
\hline Hydroxycine, clemastine & $\begin{array}{l}\text { Somnolence, }{ }^{\mathrm{w} 3} \text { anticholinergic reaction, }{ }^{\mathrm{w} 3} \text { bad taste, }{ }^{\mathrm{w} 9} \text { local skin } \\
\text { reaction }\end{array}$ \\
\hline
\end{tabular}

cimetidine $2-5 \mathrm{mg} / \mathrm{kg}$, ${ }^{\mathrm{w} 6}$ oral methylprednisolone $2 \times 32 \mathrm{mg},{ }^{\mathrm{w} 2}$ and intravenous prednisolone $250 \mathrm{mg}$ were tested." ${ }^{\mathrm{w}}$ The outcomes were bronchospasm, angio-oedema (with urticaria), and laryngeal oedema; we regarded all as potentially life threatening. Four of 391 (1\%) patients who received an antihistamine had a respiratory symptom compared with 9/394 (2.3\%) controls (odds ratio $0.46,0.15$ to 1.39 ) (fig 2). Of patients who received a steroid, $3 / 778(0.4 \%)$ had a respiratory symptom compared with $11 / 769(1.4 \%)$ controls (odds ratio $0.31,0.11$ to $0.88)$. Finally, in one trial, $1 / 196(0.5 \%)$ patients who received the clemastine-cimetidine combination had angio-oedema compared with $8 / 194(4.1 \%)$ controls (odds ratio $0.20,0.05$ to 0.76 ). ${ }^{\text {w6 }}$

Six trials reported on cutaneous symptoms. Oral hydroxyzine $100 \mathrm{mg}$, w3 intravenous dimenhydrinate $25 \mathrm{mg}{ }^{\text {w8 }}$ subcutaneous chlorpheniramine $10 \mathrm{mg},{ }^{w 7}$ intravenous clemastine $2 \mathrm{mg}^{\mathrm{w9}}$ or $0.03 \mathrm{mg} / \mathrm{kg}^{\mathrm{w}}{ }^{\mathrm{w} 6}$ intravenous prednisolone $250 \mathrm{mg}$, ${ }^{\mathrm{w} 6}$ and oral methylprednisolone $2 \times 32 \mathrm{mg}$ were tested. ${ }^{\mathrm{w} 2}$ The outcomes were urticaria, erythema, hives, pruritus, and flushing; we regarded none of these as life threatening. Fourteen of $711(2 \%)$ patients who received an antihistamine had cutaneous symptoms compared with $49 / 801(6.1 \%)$ controls (odds ratio $0.36,0.22$ to 0.60 ; P for heterogeneity $=0.03, I^{2}=62 \%$ ) (fig 2). With steroids, $5 / 778(0.6 \%)$ patients had cutaneous symptoms compared with $15 / 769$ (2\%) controls (odds ratio $0.36,0.15$ to 0.87 ).

\section{Symptom categories (grades)}

Among the three grades of symptoms, we regarded only grade 3 reactions as potentially life threatening (table 2, fig 3 ). ${ }^{\mathrm{w} 1 \mathrm{w} 2}$ Grade 1 reactions were significantly reduced with the double dose but not with the single dose methylprednisolone regimen: 87/3093 $(2.8 \%)$ patients who received the double dose regimen had a grade 1 reaction compared with 89/2178 (4.1\%) controls (odds ratio $0.62,0.46$ to 0.84 ) (fig 3 ). Grade 2 reactions were not significantly reduced, either with the single dose or with the double dose methylprednisolone regimen. Grade 3 reactions were significantly reduced only with the double dose regimen: 7/3093 $(0.2 \%)$ patients who received the double dose regimen had a 


\section{Research}

grade 3 reaction compared with 20/2178 (0.9\%) controls (odds ratio $0.28,0.13$ to 0.60 )

\section{Non-specific symptoms}

The trials reported on a large number of symptoms that we did not consider to be allergy related or life threatening (table 2). We did not analyse these any further.
Adverse drug reactions

Patients who received dexamethasone reported dyspepsia, insomnia, bitter taste, nausea, and headache (table 2). ${ }^{\mathrm{w} 2 \mathrm{w} 5}$ Patients who received hydroxyzine or clemastine reported bad taste, local skin reaction, and somnolence. ${ }^{\text {w3 } \mathrm{w} 9}$

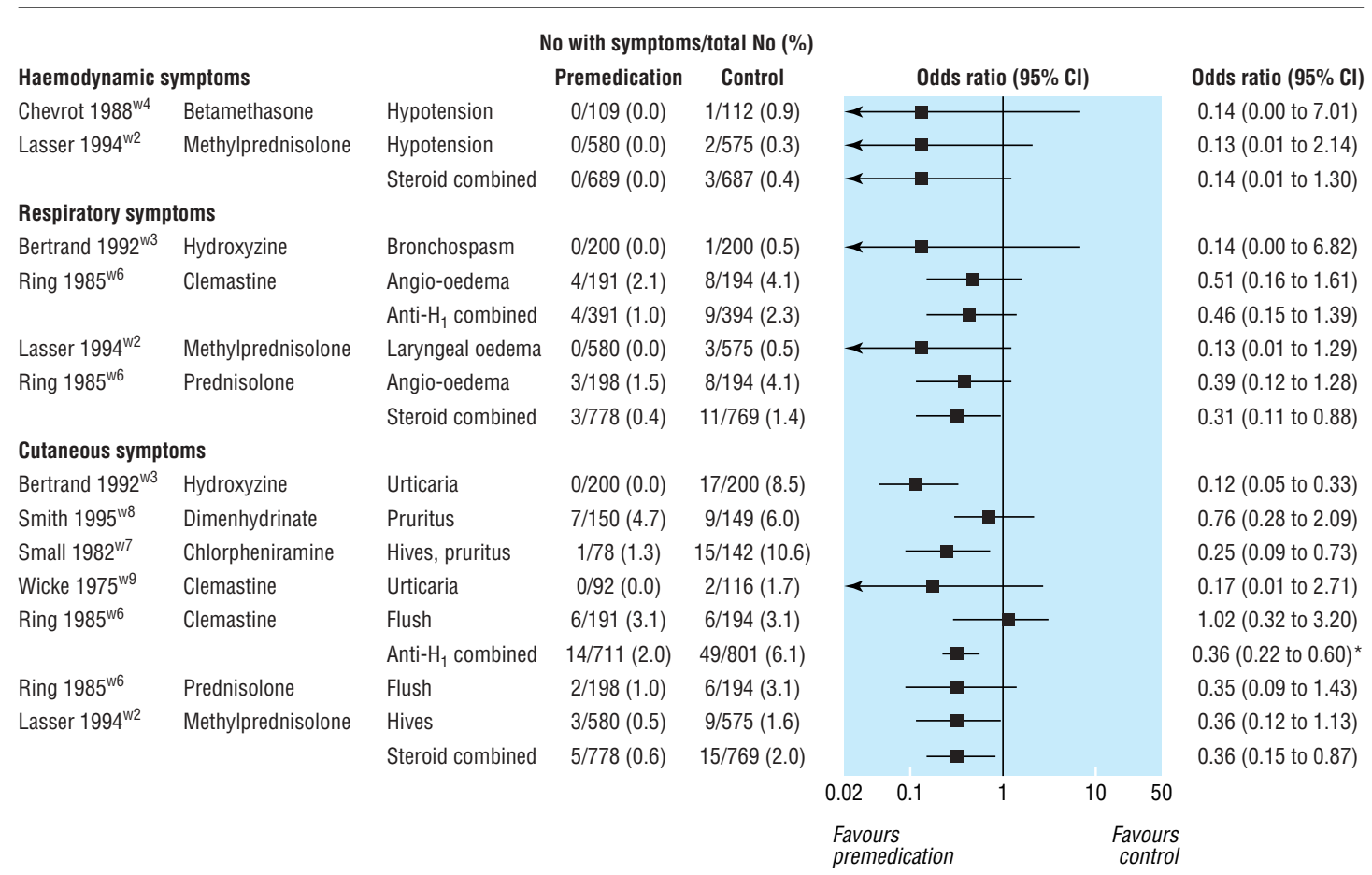

Fig 2 Distinct haemodynamic, respiratory, and cutaneous symptoms. Hypotension, bronchospasm, angio-oedema, and laryngeal oedema were considered to be potentially life threatening. Anti- $\mathrm{H}=$ antihistamine. ${ }^{\star} P$ for heterogeneity $=0.03, P=62 \%$

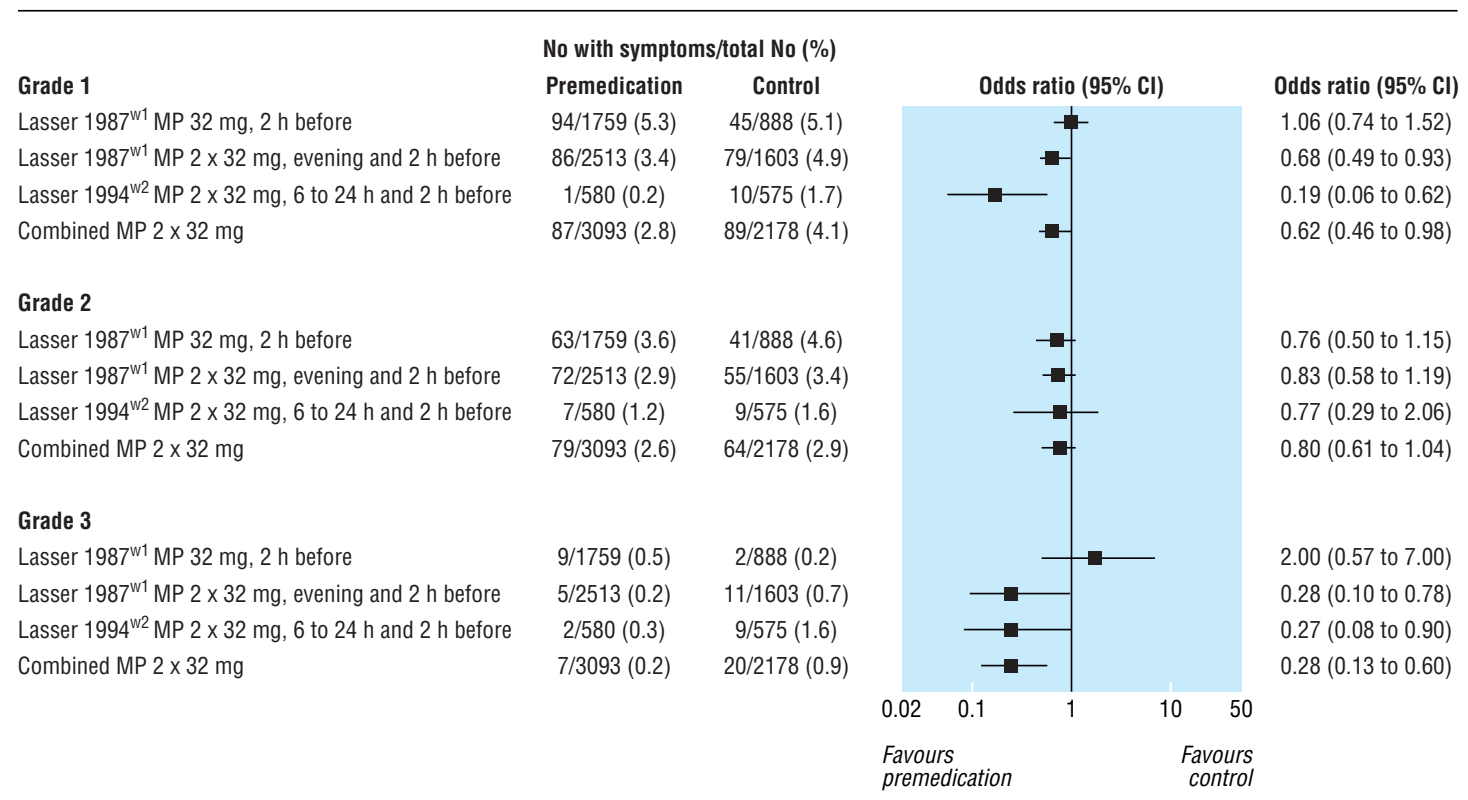

Fig 3 Arbitrary symptom combinations ("grades") as defined in the original reports. ${ }^{\text {w1 }}$ w2 Grade 1=single episode of emesis, nausea, sneezing, or vertigo; grade 2=hives, erythema, emesis more than once, or fever or chills (or both); grade 3=shock, bronchospasm, laryngospasm or laryngeal oedema, loss of consciousness, convulsions, fall or rise in blood pressure, cardiac arrhythmia, angina, angio-oedema, or pulmonary oedema. Grade 3 was considered to be potentially life threatening. $\mathrm{MP}=$ methylprednisolone (oral) 


\section{Discussion}

With steroid premedication, the incidence of respiratory symptoms in patients who received iodinated contrast media was reduced from $1.4 \%$ to $0.4 \%$ (fig 2), and the incidence of an arbitrary combination of respiratory and haemodynamic symptoms (grade 3) was reduced from $0.9 \%$ to $0.2 \%$ (fig 3). Thus, to prevent one episode of a potentially life threatening, iodinated contrast medium related reaction, about 100 to 150 patients need to receive steroids prophylactically. Likewise, the clemastinecimetidine combination showed statistically significant efficacy but for prevention of angio-oedema only and in a single trial with a limited number of patients. We found further results in favour of premedication: $\mathrm{H}_{1}$ antihistamines and steroids reduced the risk of cutaneous symptoms, and a double dose methylprednisolone regimen reduced the risk of yet another arbitrary symptom combination including sneezing, nausea, emesis, and vertigo (grade 1). For other drugs (for example, ephedrine) or drug combinations (for example, steroid-antihistamine), we could retrieve no valid data.

Disastrous anaphylactic complications after administration of iodinated contrast media seem to be rare. In the analysed trials, more than 10000 patients received an iodinated contrast medium; we found no reports of death, cardiopulmonary resuscitation, irreversible neurological deficit, or prolonged hospital stay. In a series including more than 6700 patients who received a non-ionic iodinated contrast medium, no life threatening reaction was seen. ${ }^{10}$ In more than 337000 patients who received iodinated contrast media, two deaths occurred, but a causal relationship to the contrast medium could not be established. ${ }^{11}$

\section{Potential limitations}

Our analysis has some limitations. Firstly, none of the trials included only patients with a history of allergic reactions. It may be argued that premedication is given exclusively to high risk patients, such as those with a history of allergic reaction to iodinated contrast media, and that in these selected patients premedication will certainly be beneficial. However, although three trials excluded patients with a history of a reaction to iodinated contrast media, six did not; we may thus assume that these trials represent daily clinical practice. It is unlikely that conscious selection of low risk patients in the original trials was responsible for the disappointing degree of efficacy of premedication. Also, premedication may not necessarily be efficacious in a patient with a positive history. Indeed, breakthrough reactions after steroid premedication have been observed. ${ }^{12}$ In a retrospective survey, breakthrough reactions were similar to the patients' initial reactions in $85 \%$ of cases and severe or life threatening reactions occurred in $24 \%$ of the cases. ${ }^{13}$

Secondly, a large variety of symptoms were reported. The decision as to whether a symptom was allergy related, and whether a symptom could be regarded as potentially life threatening, had to be made on the basis of clinical features that were described in the original reports; we cannot rule out selection bias. Six trials reported on symptoms that could be regarded as potentially life threatening. ${ }^{\text {w1-w4 }}$ w6 ${ }^{\text {w8 }}$ Although bronchospasm or laryngeal oedema may represent a certain threat to the patient, most of the reported symptoms were clinically of minor importance. Curiously, grade 1 and grade 3 reactions were significantly reduced but grade 2 reactions were not. However, for composite outcomes to be appropriate the individual symptoms need to be well defined, to be of equal importance, and to occur with similar frequencies; additionally, the active treatment needs to lead to a similar reduction in the risk of all components. ${ }^{14}$ No evidence exists to show that this is the case for the three arbitrarily defined gradings that were reported in the two largest trials. ${ }^{\text {w1 } 22}$

Thirdly, contrast media that are used today may have a more favourable risk profile than the tested iodinated contrast media. In a large scale Japanese survey, ${ }^{11}$ severe reactions occurred in about $0.2 \%$ of patients with high osmolar iodinated contrast media and in only about $0.04 \%$ with low osmolar non-ionic contrast media. However, when the baseline risk is very low, as with low osmolar non-ionic contrast media, prevention of allergic reactions is likely to become even less efficacious.

Finally, the average quality of these trials was limited. We do not know whether this was because of inadequate conduct or reporting of the trials. All were published before the first CONSORT checklist. ${ }^{15}$ Low quality trials are prone to bias. Empirical evidence shows that, for instance, selection bias due to inadequate randomisation or observer bias due to lack of blinding may lead to an overestimation of the effect of a treatment. ${ }^{16}$ If such biases existed in these trials, we may infer that our effect estimates even overestimated the true degree of efficacy.

\section{Arguments for and against premedication}

An argument in favour of premedication is that serious non-fatal anaphylactic reactions may contribute to major morbidity, prolonged hospital stays, and excess cost. In hospitals with limited resources and personnel who infrequently manage reactions to iodinated contrast media, an even larger number of patients that need to be treated for one to benefit may justify the use of premedication. Some may argue that our analyses are simplistic as they do not consider the potentially additive or synergistic effect of drug combinations. Indeed, drug combinations have been widely advocated ${ }^{37}$ and have been recommended in guidelines. ${ }^{4} \mathrm{H}_{1}$ antihistamine mainly showed efficacy against cutaneous symptoms, and steroids prevented respiratory symptoms. Thus, combining these drug may be justified to further improve efficacy. This, however, needs to be formally tested in randomised trials as none of the retrieved trials tested a steroid-antihistamine combination.

Arguments against premedication include the cost and the risk of doing more harm than good to the patients. Although an oral double dose steroid regimen may not be excessively expensive, a large number of patients need to be treated for one to benefit. Potentially life saving radiological interventions may be delayed by prolonged drug prophylaxis with doubtful efficacy. Pretreatment may create a sense of security among people who inject contrast media. Healthcare providers may neglect appropriate measures to survey patients and to treat anaphylaxis. Finally, the drugs used may cause harm. No serious problems were reported with steroids. However, in susceptible patients, even a single steroid dose may lead to considerable adverse effects. ${ }^{17}$ Incremental cost effectiveness ratios, taking into account all potential costs (drug cost, prolonged hospital stay, delay in diagnosis, unplanned admission to the intensive care unit) would be needed for rational decision making.

\section{Conclusions}

The existing evidence suggests that a large number of unselected patients need to receive an oral double dose of methylprednisolone to prevent a potentially life threatening, iodinated contrast medium related reaction in one of them. For antihistamines, limited evidence shows that they may prevent some reactions. Valid data supporting the efficacy of drug combinations or the use of premedication in patients with a history of allergic reactions are completely lacking. Severe allergic reactions due to contrast media seem to be rare; this may explain why no reports of disastrous reactions exist. Allergologic evaluation including 


\section{Research}

cutaneous tests and biological assessment to identify and eliminate the culpable agent has been proposed in all patients with a history of an anaphylactic reaction to a contrast medium. ${ }^{18}$ However, only a fraction of patients with severe and life threatening reactions have a positive skin test for the administered contrast material. ${ }^{2}$ Another approach would be to train physicians who are using iodinated contrast media to recognise and treat anaphylactic reactions appropriately. ${ }^{190}$ Accordingly, radiology departments should be staffed with the necessary equipment for resuscitation. ${ }^{\text {w4 }}$ Physicians dealing with patients receiving contrast media should not rely on the efficacy of premedication; routine prophylaxis should be abandoned.

We thank M Daniel Hake, Medical Library, Medical Faculty, Geneva University, for his help in searching electronic databases.

Contributors: MRT initiated, designed, and organised the study and cross checked and analysed extracted data; he is the guarantor. EvE searched and extracted data. PL cross checked extracted data. $\mathrm{CH}$ designed the study and cross checked extracted data. All authors participated in interpreting the results of the trials and in writing the paper.

Funding: MRT was a beneficiary of a PROSPER (Program for Social Medicine, Preventive and Epidemiological Research) grant from the Swiss National Research Foundation (No 3233-051939.97/2 and No 3200064800.01/1)

Competing interests: None declared.

1 Andrew E, Berg KJ. Nephrotoxic effects of X-ray contrast media.J Toxicol Clin Toxicol 2004;42:325-32

\section{What is already known on this topic}

Premedication with steroids, antihistamines, and other drugs, alone or in combination, is widely used before injection of iodinated contrast media

Premedication is thought to reduce the risk of life threatening anaphylactic reactions

\section{What this study adds}

Life threatening anaphylactic reactions due to iodinated contrast media are rare

In unselected patients, the usefulness of premedication is doubtful as a large number of patients need to receive premedication to prevent one potentially serious reaction

Data supporting the use of premedication in patients with a history of allergic reactions are lacking
2 Laroche D, Aimone-Gastin I, Dubois F, Huet H, Gerard P, Vergnaud MC, et al. Mechanisms of severe, immediate reactions to iodinated contrast material. Radiology 1998;209:183-90.

3 Greenberger PA, Patterson R. The prevention of immediate generalized reactions to radiocontrast media in high-risk patients. J Allergy Clin Immunol 1991;87:867-72.

4 American College of Radiology. Patient selection and preparation strategies. In: Manual on contrast media. www.acr.org/s_acr/sec.asp? $\mathrm{CID}=2131 \& \mathrm{DID}=16687$ (accessed 11 May 2006)

5 Morcos SK, Thomsen HS, Webb JA. Prevention of generalized reactions to contrast media: a consensus report and guidelines. Eur Radiol 2001;11:1720-8.

6 Lieberman P. The diagnosis and management of anaphylaxis: an updated practice parameter. J Allergy Clin Immunol 2005;115:S483-523.

7 Robertson PS, Rhoney DH. Prophylaxis for anaphylactoid reactions in high risk Robertson PS, Rhoney DH. Prophylaxis for anaphylactoid reactions in
patients receiving radiopaque contrast media. Surg Neurol 1997;48:292-3.

8 Higgins JP, Thompson SG, Deeks JJ, Altman DG. Measuring inconsistency in meta-analyses. BMJ 2003;327:557-60.

9 Lasser EC, Berry CC, Talner LB, Santini LC, Lang EK, Gerber FH, et al. Protective effects of corticosteroids in contrast material anaphylaxis. Irvest Radiol 1988;23(suppl 1):S193-4.

10 Munechika H, Hiramatsu Y, Kudo S, Sugimura K, Hamada C, Yamaguchi K, et al. A prospective survey of delayed adverse reactions to iohexol in urography and computed tomography. Eur Radiol 2003;13:185-94.

11 Katayama H, Yamaguchi K, Kozuka T, Takashima T, Seez P, Matsuura K. Adverse reactions to ionic and nonionic contrast media: a report from the Japanese Committee on the Safety of Contrast Media. Radiology 1990;175:621-8.

12 Mohan JC, Reddy KS, Bhatia ML. Anaphylactoid reaction to angiographic contrast media: recurrence despite pretreatment with corticosteroids. Cathet Cardiovase 1984;10:465-9.

13 Freed KS, Leder RA, Alexander C, DeLong DM, Kliewer MA. Breakthrough adverse reactions to low-osmolar contrast media after steroid premedication. Am J Roentgenol 2001;176:1389-92.

14 Montori VM, Permanyer-Miralda G, Ferreira-Gonzalez I, Busse JW, Pacheco-Huergo V, Bryant D, et al. Validity of composite end points in clinical trials. BMJ 2005;330:594-6.

15 Begg C, Cho M, Eastwood S, Horton R, Moher D, Olkin I, et al. Improving the quality of reporting of randomized controlled trials: the CONSORT statement. JAMA 1996;276:637-9.

16 Schulz KF, Chalmers I, Hayes RJ, Altman DG. Empirical evidence of bias: dimensions of methodological quality associated with estimates of treatment effects in controlled

17 Pasternak JJ, McGregor DG, Lanier WL. Effect of single-dose dexamethasone on blood glucose concentration in patients undergoing craniotomy. J Neurosurg Anesthesiol 2004;16:122-5.

18 Dewachter P, Trechot P, Mouton-Faivre C. Anaphylactoid reactions to contrast media: literature review (article in French). Cah d'Anesthésiol 2003;51:341-54.

19 Bartlett MJ, Bynevelt M. Acute contrast reaction management by radiologists: a local audit study. Australas Radiol 2003;47:363-7.

$20 \mathrm{O}^{\prime}$ Neill JM, McBride KD. Cardiopulmonary resuscitation and contrast media reactions in a radiology department. Clin Radiol 2001;56:321-5.

(Accepted 4 July 2006)

doi 10.1136/bmj.38905.634132.AE

Division of Anaesthesiology, Geneva University Hospitals, CH-1211 Geneva, Switzerland

Martin R Tramèr reader in anaesthesia

Department of Radiology, Geneva University Hospitals

Pierre Loubeyre staff radiologist

Allergy Unit, Division of Immunology and Allergy, Geneva University Hospitals

Conrad Hauser associate professor

Department of Social and Preventive Medicine, University of Bern, CH-3012 Bern, Switzerland

Erik von Elm research fellow

Correspondence to: M Tramèr martin.tramer@hcuge.ch 